\title{
Employment and Career Status of People with Disabilities
}

\author{
Osa-Edoh, G.I. PhD \\ University of Benin, Benin City
}

\begin{abstract}
This paper investigates the employment and career status of people with disabilities. It examines the challenges and developing career goals, and plans of action. Providing career development services to people with disabilities has always been a challenge to career counsellors. Generally, the vocational adjustment of people with disabilities has been characterized by limited salable work skills, low income, underemployment, unemployment (Curnow, 1989). In addition, Harrington (1997) opined that students with disabilities frequently leave school without marketable skills or the ability to function independently. Such students therefore lack the opportunity to participate in decision making, to form a perception of oneself as a worker, they lack self competences and this can impede career development. The disempowering nature of these classification systems is often all too apparent to people with disabilities applying for rehabilitation services in an effort to enhance self sufficiency and personal independence (Scotch 2000).rather than being treated as adults with free or equal status, they may be confronted by able bodied persons asserting a right to determine what kind of services they need. Thus, it is critically important that career counsellors reject paternalistic castification processes and activity work to foster empowerment among their clients with disabilities.Empowering People with Disabilities through Career CounsellingThree milestone pieces of Federal legislation passed in the 1990's set a tone of empowerment and choice regarding service provision to people with disabilities and consumer movement among people with disabilities originally begun in the 1960's. These pieces of legislation are the Americans with Disabilities Act of 1990 (ADA), the 1992 Rehabilitation Act Amendments, and the Ticket to Work and Work Incentives Improvement Act of 1999. Effective career counselling can thus be instrumental for empowering the life choices and career success of clients with disabilities. Apply career counselling structure within an empowerment framework will enable clients with disabilities to become active and well informed.
\end{abstract}

\section{Introduction}

The world of work is changing at a rapid pace and the changes are likely to accelerate during the twenty -first century. Employment arrangement such as temporary employment, short term hires, contractual positions, leased workers, and on call and part time workers have and will continue to influence the career development of all workers (Institute on Rehabilitation Issue, 1999). These changes are having a substantial impact on the life roles of individuals with disabilities, the settings in which they life and work, and the events that occur in their lives. At the same time, current disability policy in the United State and other countries in the World focuses on the inclusion, independent, and empowerment of people with disabilities (Kosciulek, 2000). Thus, career counselling of people with disabilities must be a dynamic, creative, and highly individualized process. Effective career counseling can be instrumental for empowering the life choices inclusion, and independence of people with disabilities. In turn, empowerment, inclusion and independence will lead to high-quality employment and fulfilling careers for individual with disabilities (O'Day, 1999). Assisting people with disabilities in finding suitable employment is becoming an increasingly difficult task due to the ever-changing nature of work. Major trends such as globalization of the America economy, technology, and population shifts are changing the nature of work and worker skill requirements (Ryan, 1995). Despite rehabilitation efforts, a majority of Americans with disabilities between the ages of 16 and 64 are not employed and their numbers between the ages of 16 and 64 are not employed and their 
numbers have not changed since 1986, despite the fact that a majority of non-employed people with disabilities in the working age population wants to work (National Organization on Disability, 2000; Taylor, 1994). Given that work is a central force in peoples' lives, dramatically high rates of employment and underemployment an adversely affect not only economic and social status of individuals with disabilities, but also their self image. Disability therefore, is a risk factor that should be carefully considered when providing career planning, preparation, and counseling services to individuals with disabilities (Szymanski \& Hanley-Maxwell, 1996).

\section{Specific Difficulties Faced by People with Disabilities}

Providing career development services to people with disabilities presents a challenge to career counsellors. In general, the vocational adjustment of people with disabilities has been characterized by limited salable work skills, low income, underemployment, and unemployment (Curnow, 1989). In addition, according to Harrington (1997), students with disabilities frequently leave school without marketable skills or the ability to function independently. The discouraging report on the vocational preparation and employment outcome for people with disabilities (Roessler, 1987; Wolfe, 1997) highlights the need for improved career counselling services for this population. A distinct set of challenges encountered by many people with disabilities that can be used as a reference point for the practicing career counsellor includes: (a) limitations in early life experiences, (b) decision making difficulties, and (c) a negative worker self concept as result of castification processes in service delivery systems.

\section{Limitations in Early Experiences}

Frequently, people with disabilities arrive at adulthood with few career options (Chubon, 1995). Limited early vocational and social experiences encountered by people with disabilities restrict the array of career options they perceive, impede decision-making ability, and impair future vocational development. The effect of limited early vocational experiences has been described by Holland (1985) as a precursor to the development of career related problems. Specific career development problems resulting from limited vocational experiences may include the failure to develop a consistent and differentiated personality pattern a clear vocational identity, and the establishment of a career in a incongruent occupation (Holland, 1985). Unfortunately, such developmental patterns are not unusual among people with disabilities.

\section{Decision Making Ability}

Lacking of opportunities to participate in decision making, to form a perception of oneself as a worker, and to test self competences can be the outcome of limited early experiences and can impede career development. The poorly defined self concept, ambivalence about obtaining work, and limited occupational information reported by people with disabilities (Curnow, 1989) is indicative of distortions that could result in unrealistic vocational aspirations or decisions. Harrington (1997) has aptly described how many individuals with disabilities have had little opportunity for successful experience in decision making-and, therefore, lack competence in making decisions. 


\section{Negative Worker Self Concept Resulting From Castification Processes}

Lack of experience and difficulty in decision making are not solely the result of disability, but also an outcome of social attitudes and stereotypes. Social attitudes toward disability may be as important as the disability itself in that the negative attitude of other plays a part in shaping the life role of the individual with disability. The outcome of this long term exposure to prejudicial attitudes may result in a negative self appraisal and a negative worker self concept.

Society generally holds diminished expectations for people with disabilities (Schroeder, 1995). These attitudes are pervasive; they influence all of us to same degree. As a class, people with disabilities have suffered discrimination. Individuals with disabilities (Fine \& Asch, 1988), similar to members of racial and ethnic minority groups (Trueb, 1993), face common social problems of stigma, marginality, and discrimination. Further, given that disability rates among racial and ethnic minority group members are proportionally higher than rates in the population overall (Rehabilitation Services Administration, 1993) many individuals with disabilities face double jeopardy.

Szymanskin and Trueba (1994) maintained that a least some of the difficulties faced by people with disability are not the result of functional impairments related to the disability, but rather are the result of castification processes embedded in societal institutions for rehabilitation and education and enforced by well meaning professionals. Castification processes have their roots in a determinist view in which people who are different are viewed as somehow less "human" or less capable (Trueba, Cheng, \& Ima, 1993). Problems of catification plague services to people with disabilities because the same categories of impairment and functional limitation (constructed mostly by people with disabilities) are used to determine eligibility for services to prescribe interventions, and on occasion, to explain failure. The constructs and those who use them become agents of castification (Szymanski \& Trueba, 1994).

The disempowering nature of these classification systems is often all too apparent to people with disabilities applying for rehabilitation services in an effort to enhance self sufficiency and personal independence (Scotch, 2000). Rather than being treated as adults with free or equal status, they may be confronted by able bodied persons asserting a right to determine what kinds of services they need. Thus, it is critically important that career counselors reject paternalistic castification processes and actively work to foster empowerment among their clients with disabilities. To aid you in accomplishing this task, below is presented an empowerment framework useful for providing career counselling services to people with disabilities.

\section{Empowering People with Disabilities through Career Counselling}

Three milestone pieces of federal legislation passed in the 1990's set a tone of empowerment and choice regarding service provision to people with disabilities and rejuvenated the consumer movement among people with disabilities originally begun in the 1960's. These pieces of legislation are the Americans with Disabilities Act of 1990 (ADA), the 1992 Rehabilitation Act Amendments, and the Ticket to Work and Work Incentives Improvement Act of 1999. 


\section{Americans with Disabilities Act of 1990}

Barriers to employment, transportation, public accommodations, public services, and telecommunications have imposed staggering economic and social costs on U.S. society and have undermined our well intentioned efforts to educate, rehabilitate, and employ individuals with disabilities. The intent of the ADA is to break down these barriers and, thereby enable society to benefit from the skills and talents of individuals with disabilities (Pardeck, 2001). The ADA gives civil rights protections to individuals with disabilities similar to those proved to individuals on the basis of race, colour, sex, national origin, age, and religion. It guarantees equal opportunity for individuals with disabilities in public accommodations, employment, transportation, state and local government services, and telecommunications (U.S. Equal Employment Opportunities Commission, 1992).

The practices and activities covered by the employment nondiscrimination requirements of the ADA are of particular importance to career counsellors. The ADA prohibits discrimination in all employment practices, including job application procedures, hiring, firing, advancement, compensation, training, and other terms, conditions, and privileges of employment. In addition, it applies to recruitment, advertising, tenure, layoff, leave, fringe benefits, and all other employment related activities. Employment discrimination is prohibited against " qualified individuals with disabilities." This includes applicants for employment and employees. An individual is considered to have a "disability" if he or she has a physical or mental impairment that substantially limits one or more major life activities, has a record of such an impairment, or is regarded as having such an impairment. The society for Human Resource Management (2000) has found that the ADA has been beneficial in all phases of the employment process for both employers and individuals with disabilities seeking employment and/or needing accommodations in an existing position.

\section{Rehabilitation Act Amendment}

In the opening of the 1992 Rehabilitation Act Amendments, similar to information in the ADA and other data provided earlier in this chapter, congress reported that individuals with disabilities continually encounter various forms of discriminations in such critical area as employment, housing, public accommodation, education, transportation, communication, and recreation. The explicit purpose of the Amendments is therefore to empower individuals with disabilities to maximize employment, economic self-sufficiency, independence, and inclusion and integration into society (Rehabilitation Services Administration, 1993). A particular focus of the legislation is the increase emphasis on client choice in the services provision process. The choice provisions go beyond simply the right of a client to be involved actively in the selections of a service provider. The Act also broadens a clients' participation in the selection of a vocational goal (Schroader, 1995). Following passage of the 1992 amendments, a state vocational rehabilitation (VR) agency must consider an individual unique strengths, resources. Priorities, concerns, abilities, and capabilities in the selection of an employment outcome. 
In this way, congress made a clear statement that the purpose of the VR program is not simply to find a person a job, but a good job with a promising future that will allow the individual to raise him or herself out of poverty and to live a life of real dignity. In other words, the responsibility of the vocational rehabilitation system is to help impart an elevated expectation for people with disabilities coming to the system for help. While focused on the services provided through the state federal VR system, the philosophical tenets and practical implications of the Act are useful and valid for any counselors providing career services to people with disabilities. The goal of empowering people with disabilities to live independent, enjoy self determination, make choices, contribute to society, and pursue meaningful careers should be a common one for all professionals serving individuals with disabilities.

\section{Ticket to Work and Work Incentives Improvement Act of 1999}

The Ticket to Work and Work Incentives Improvement Act of 1999 (Ticket to Work) is the most significant disability related legislation since the ADA. It is federal legislation related to increasing employment opportunities for individuals with disabilities who are Social Security Disability Insurance (SSDI) and Supplemental Security Income (SS) recipients. The ticket to work is designed to remove the primary disincentive that prevents people with disabilities from entering or re-entering the workforce, which is loss of health insurance benefits. In addition, this legislation makes real the opportunity for client choice in the employment and rehabilitation system is not effective in getting people with disabilities back to work once they become SSDI or SSI recipients.

The ticket to Work, consistent with an empowerment philosophy of career counseling, encourages client choice in the selection of employment related rehabilitation services. Essentially, the Ticket to Work represents the deregulation of vocational rehabilitation because it mandates client choice of rehabilitation services providers. In deregulation sequence, choice, in turn, is followed by increased competition, increased variety of services, increased quality of services, increase client satisfaction with services, and reduced costs of services. In sum, the Ticket to Work enhances the employment services system and increases the significance of the role of the career counselor by introducing a voucher system and extending Medicare and Medicaid coverage for people with disabilities.

\section{An Empowerment Philosophy}

The ADA, Rehabilitation Act Amendments of 1992, and Ticket to Work have served to fuel the expansion of an empowerment philosophy in disability and rehabilitation services. While some people with disabilities may receive vocational services exclusively from the state federal VR system, it is important that all career counselors be aware of the philosophical tenets related to the disability empowerment movement and develop a framework for providing career counseling service from an empowerment perspective.

Empowerment of individuals with disabilities may be viewed as possession of the same degree of control over one's own life and the conditions that affect life as is general possessed by people without disabilities (Harp, 1994). It is the transfer of power and control of values, decisions, choices, and directions of human services such as career counselling from external entities to 
individuals themselves (Bolton \& Brooking, 1996). Thus, as hypothesized and tested by Kisciulek and Merz (2001), the career counselor committed to an empowerment approach to service delivery should facilitate and maximize opportunities for individuals with disabilities to have control and authority over their own lives.

Emener (1991) has described the philosophical tenets necessary for an empowerment approach to rehabilitation. Extended, these tenets provide a valuable philosophical framework for the provision of career counseling services to people with disabilities. The four tenets are paraphrased as follows;

1. Each individual is of great worth and dignity,

2. Every person should have equal opportunity to maximize his or her potential and is deserving of societal help in attempting to do so.

3. People by and large strive to grow and change in positive directions.

4. Individuals should be free to make their own decisions about the management of their lives.

From an empowerment perspective based on the above philosophical tenets, career counseling is not something that can be done to or for a client. Rather, it is a process in which clients must become active, informed participants who learn and control a planning process that they use for short-and long term career development (Szumnski, Hershenson, Enright, \& Ettinger, 1996). In addition, the lifelong, development nature of the process means unless we plan to work with an increasing dependent client again and again across the decades, our professional responsibility is to assure that each person learns the (career planning) process" (Mastic, 1994, p. 37).

Active client involvement is the key element of successful career counselling interventions (Ettinger, Conyers, Merz, \& Koch, 1995). In an empowerment approach to career counselling, clients are actively involved in: (a) gathering information, including self-assessment and learning about occupations and the labour market; and (b) generating alternative courses of action and weighing those alternative; and (c) formulating a plan of action. The final section of this chapter applies the structure of career counselling to people with disabilities. The information and structure provided allows you to develop the skills necessary to provide efficacious services to people with disabilities from an empowerment perspective.

\section{Applying the Career Counselling Structure to People with Disabilities}

Unfortunately, reports on the current employment and career status to people with disabilities are discouraging (National Organisation on Disability, 2000; Taylor, 1994). Many people with debilities are either unemployed or underemployed. Career challenges encountered by people with disabilities often result from a combination of limitations in life experiences and decision making difficulties. In addition, individuals with disabilities may feel empowered as a result of long term exposure to prejudicial attitudes from castification processes in service systems. The need for improved career counselling for people with disabilities cannot be overstated. An empowerment approach to career counselling is necessary to assist people with disabilities to achieve their career goals and resolve their career problems. In the section that follows, the career counseling structure is applied to people with disabilities to aid you in developing the 
skills necessary to effectively serve this population. By applying this structure to a disability context, you can be instrumental in empowering the life choices, inclusion, and independence of people with disabilities.

\section{Client Goal or Problem Identification, Clarification, and Specification}

Phase 1 of career counseling involves client goal or problem identification, clarification, and specification. In this phase, the counselor and client proceed mutually from forming the working alliance to gathering client information to understanding and hypothesizing about client information and behaviour.

\section{Opening - Forming the Working Alliance}

It is important to note at this juncture that, at least theoretically, career counseling for people with disabilities should not differ from career counselling for any other client. In practice, however, this is less than totally true, primarily because the person with a disability presents unique issues that were not presented by the population of individuals without disabilities on whom career counseling approaches were developed (Hersheson, 1996). For example, in forming the working alliance with client with a disability it is important to distinguish those whose onset of disability was pre-career (e.g., congenital or in early childhood) from those whose onset of disability was after the person had entered upon a career. As summarized by Goldberg (1992), past research has shown that people with acquired disabilities tend to choose occupations consistent with their parents ${ }^{7}$ aspirations and social class. It is critical from the onset that you have an awareness of the myriad ways disability may potentially influence a person's career development. Awareness of such disability related factors is a critical ingredient in establishing an effective working alliance (Kosciulek, Chan, Lustig, Pichette, \& Strauser, 2001).

In the opening stage of Phase 1 of career counseling, the counselor and client identity initial client goals or problems and the internal thoughts and feelings and underlying dynamics that may be involved. Ryan (1996) emphasized the importance of forming an effective working alliance in counselling people with disabilities by clearly identifying presenting problems and defining the client-counsellor relationship and responsibilities. In order for an effective and useful career counselling process to occur, clients should be encouraged to be active participants in the counseling process (Kosciulek et al, 2001). An empowerment approach to forming the working alliance in career counselling includes elements that both clients and counsellors bring to the relationship. Primary client elements include that clients (1) take responsibility for their own actions and consequences of their actions and (2) are responsible for their own decision making. Counsellor elements in the elements in the working alliance show the following characteristics:

(1) Counsellors know and admit their limitations (e.g., lack of knowledge of a specific disability condition) and (2) counsellors display unconditional positive regard for the clients they serve (National Institution on Disability and Rehabilitation Research (NIDRR), 1994). Specific counselling techniques that contribute to client empowerment and the development of an effective working alliance also include the following: 
Treating all clients as adults regardless of the severity of the disability condition.

$>$ Using age appropriate language and techniques

$>$ Placing emphasis on client strengths.

$>$ Respecting client values and beliefs.

\section{Gathering Client Information}

Following the development of an effective working alliance and the establishment of an empowerment approach to career counselling, you should proceed to gather information about the client's specific situation. A series of questions may be helpful in the information gathering process. It may be beneficial to inquire about the client's overall world view. For example, asking clients how they view themselves, others, and the world may provide valuable starting point for the career exploration process. Another question that applies directly to people with disabilities relates to the personal and environmental barriers or constraints within which a client operates. The data generated from responses to this question may give the career counsellor clues about the primary difficulties encountered by a client including limitations in life experiences and feelings of disempowerment as a result of castification processes in previous educational and vocational pursuits. A third question important to address with client with disabilities relates to their decision making styles. Simply asking a client about his or her decision making processes and the life matters on which they make decisions may elicit valuable information about the client's comfort with decision making regarding career planning.

\section{Understanding and Hypothesizing Client Behaviour}

The final stage of Phase 1 of career counselling involves understanding and hypothesizing about client information and behavior. Following the development of an empowering working alliance and gathering information about client worldviews, personal and environmental barriers, and decision making patterns, the counsellor and client are prepared to hypothesize how this information relates to the clients' career development process. At this stage, it may be instructive for you to apply the language and constructs from career development, counselling, and personality theories, and the literature and research concerning individuals with disabilities to understand and interpret client information individuals with disabilities to understand and interpret client information and behavior. Identification of the specific disability related variables (including interaction with the client's family, social, and labour market environments) that may be contributing to a career related problem or inhibiting maximal career growth may be particularly useful for the client and counsellor to focus potential actions and interventions.

\section{Client Goal or Problem Resolution}

Phase 2 of career counseling involves taking action, developing career goals, and evaluating and closing the relationships. In this phase, the counselor and client undertake actions that will begin to foster positive career progress/ identify specific career goals, close the counseling relationship to the extent necessary, and plan appropriate services for monitoring progress and assessing goal attainment, 


\section{Taking Action}

Career counselling with people with disabilities, as with all individuals, may best proceed into an action phase by using theory based counseling and assessment procedures. Empowerment counseling assists clients with striving to achieve their goal or resolve their concern in a positive atmosphere created by an effective working alliance. It is important to remember that empowerment career counseling with people with disabilities involves treating all clients as adults, using age-appropriate language and techniques, and respecting clients values and beliefs.

For example, a 20 year-old client seeking job placement assistance may present with cognitive limitations due to mental retardation. In this case, you should address the individual as you would any other 20 year-old, respecting their goal, and making accommodations as necessary for individual needs. In addition, assessment processes must be comprehensive and individualized so that you can understand client needs, wants, skills, and weaknesses. It is also particularly important to remember that client strengths play a major role in their empowerment. Assessment procedures should focus on identifying and capitalizing on these strengths in the goal development process. Protocols should also be tailored to individual needs and preferences to avoid castification and disempowering did not include individuals with disabilities in the development and norming process may further accentuate disability limitations rather than identify individual strengths.

Finally, client disabilities affect their families, spouses, friends, and other individuals who can be assets to counselling and its outcomes. In the wish to include a family member or friend in some aspect of their career counselling process (e.g., intake, client homework) to facilitate integration of information and goal-directed behavior outside of counselling sessions. Involving "significant others" (with client consent) in counselling can be a critical element in creating empowering relationships (NIDRR, 1994) and facilitating client career development

\section{Developing career goals and plans of action}

Career counselling is an active process that must be done in an empowering context. Successful goal development and interventions required active client involvement in all phases of the process. When developing career goals, clients with disabilities must be encouraged to take responsibility for (a) gathering and integrating information about themselves, occupations, and the labour market; (b) generating and evaluating alternatives; (c) making decisions and formulating plans of action; (d) implementing career plans; and (e) evaluating their results (Szymanski \& Hershenson, 1997).

A wide range of career interventions is available to assist counsellors and their clients with disabilities effective goal planning. General interventions include career planning systems, assessment tools, career classes and workshops, including those specially designed for people with disabilities, and career portfolios. Career interventions which may accompany school to work transition, adult training, and direct job placement programmes include apprenticeship, cooperative education, school based enterprises/ entrepreneurship, internships and practical, and community based volunteerism. As discussed by Wolfe (1997), the use of a combination of both 
individual and group based career counselling and job search interventions has a positive effect on the employment status of individuals with disabilities.

Two major rehabilitation approaches are also highly applicable to the career counselling goal identification and development of people with disabilities. One of these is supported employment, which provides ongoing, work related supportive services that permit persons with severe disabilities to engage in competitive employment. A second approach is job accessible to workers with disabilities (Hershenson, 1996). By allowing for exploration and attending to specific disability-related factor that may be accommodation processes may greatly assist client and counsellors with identifying realistic and satisfying career options. As people with disabilities are a heterogeneous population, no single counselling, assessment, or intervention approach will be applicable to all individuals with disabilities. Therefore, as with all career counselling clients, the focus should be eclectic, that is identifying and meeting individual needs, removing specific barriers, expanding the person's range of options, and supporting the person through his or her transition to work (Szymanski \& Hershenson, 1997).

\section{Evaluating Results and Closing Relationships}

As previously stated, active client involvement is the key element of most successful career counselling interventions. A critical question at the close of a career counselling relationship with individuals with disabilities is whether the client was actively involved in (a) gathering information, (b) generating alternative courses of action and weighing those alternatives, and (c) formulating a plan of action. The quality of the working alliance, level of empowerment generated, usefulness of interventions, and appropriateness of career goals identified are likely to be closely related to the answer to this question.

A critical ingredient for successful career development of people with disabilities is effective follow-along and follow up services. Thus, when closing the career counseling relationship, counsellors and clients may want to establish a monitoring process to ensure achievement of established career plans (e.g., completion of an educational or vocational training programme, or success job maintenance). Follow along services that are not intrusive but continue to support empowerment can be critical for achieving desired long-term outcomes. Counsellors should recognized that clients might choose to discontinue ongoing supports at any lime. Counsellors should not foster dependency, because clients may see too much follow up as lack of confidence. An empowered client will feel free to re-initiate counselling contacts if the need arises (NIDRR, 1994).

Once clients leave counselling, their success may depend on their ability to access community resources. Counsellors can enhance self reliance by teaching clients how to get information and tap into supportive workplace and community networks. Clients who discover and utilize community based resources will be more independent and transfer their personal empowerment beyond the counselling arena into all realms of life.

\section{Closing Thoughts}

Due to the ever changing nature of the world of work and service system castification processes, assisting people with disabilities to achieve positive, challenging, and stimulating career 
development is an increasingly difficult task. Effective career counselling can thus be instrumental for empowering the life choices and career success of your clients with disabilities. The information provided in this chapter should help you expand your counselling repertoire to include those skills and techniques necessary to effectively serve people with disabilities. Applying the career counselling structure within an empowerment framework will enable your clients with disabilities to become active, informedparticipants who learn and control a planning process that they use for both short and long term career development. In this manner, you will promote opportunities for your clients with disabilities to have control and authority over their own lives.

\section{References}

Bolton, B, \& Brookings, J. (1996).Development of a multifaceted definition of Empowerment Rehabilitation Counseling Bulletin. 39(4), 256-264.

Chubon, R.A. (1995). Career related needs of school children with severe physical disabilities. Journal of Counseling and Development, 64,47-51.

Curnow, T.C. (1989). Vocational development of persons with disability. The Career Development Quarterly, 37.269-278.

Dart, J. (1992, September). Toward equality and empowerment. Paper presented at the IBM Conference on Full Participation in a Modern Society, Tokyon, Japan.

Emener, W. (1991), empowerment in rehabilitation: An empowerment philosophy for rehabilitation in the $20^{\text {th }}$ Century. Journal of Rehabilitation, 57(4), 7-12.

Emener, J. Conyers, L., Merz, M.A. \& Koch, L. (1995).Strategies and tools for counselors, educators, and consumers.(Working paper No. 3). Madison, WI: University of WisconsinMadison; Rehabilitation Research and Training Centre.

Fine, M, \&" Asch, A. (1988). Disability beyond stigma: social interaction, discrimination, and activism, journal of social issue, 44, 3-21.

Goldberg, R.T. (1992). Toward a model of vocational development of people with disabilities Rehabilitation counseling Bulletin, 35,161-173.

Hanger, D, \& Marrone, J. (1995). Empowerment issues in services to individuals with disabilities. Journal of Disability Policy Studies, 6(2), 17-36.

Harp, H.T. (1994).Empowerment of mental health consumers in vocational rehabilitation Psychological Rehabilitation Journal, 17, 83-90.

Hershension, D.B. (1996). Career counseling. In Dell Orto, A.E., \& Marinelli, R.P. (Eds.) Encyclopedia of disability and rehabilitation (pp. 140-146).New York: Simon \& Schuster Macmillan. 
Holland, J.L. (1985). Making vocational choices: A theory of vocational personalities and work environments $\left(2^{\text {nd }} E d\right)$. Englewood Cliffs, NJ: Prentice Hall.

Holmes, G.K (1993). The historical roots of the empowerment dilemma in vocational rehabilitation, Journal of Disability Policy Studies, 4(1), 1-19.

Institute on Rehabilitation Issues (1999).Meeting future workforce needs. Stout Vocational Rehabilitation Institute, University of Wisconsin Stout, Menomonie, WI.

Kosciulek, J.K (2000). Implications of consumer direction for disability policy development and rehabilitation service delivery. Journal of Disability Policy Studies. 11(2), 82-89.

Kosciulek, J.F. Chan, F., Lustig, D, Pichette, E, \& Strauser, D. (2001, October).The working alliance: A critical element in the rehabilitation counseling process. Paper presented at the alliance for Rehabilitations Counselling symposium, St. Louis, MO.

Kosciulek J.F. \& Merz M.A. (2001). Structural analysis of the consumer directed theory of empowerment. Rehabilitation counseling Bulletin, 44/ 209-216.

Mandeville, $K$, \& Brabham, R. (1992) .The federal state vocational rehabilitation program. In R.M. Parker \& E.M. Szymanski (Eds), rehabilitation counseling: Basics and beyond ( $2^{\text {nd }}$ ed, pp. 43-71). Austin, TX: Pro-Ed.

Mastie, M.M. (1994). Using assessment instruments in career counseling: career assessment as compass, credential, process and empowerment. In J.T. Kapes, M.M. Mastie, \& E.A. Whitefield (eds.) Acounselor's guide to career assessment instrument ( $3^{\text {rd }}$ Ed., Pp. 31-40). Alexandria, VA: The National Career Development Association.

National Institute on Disability and Rehabilitation Research (1994). Empowerment counseling: Consumer counselor partnerships in the rehabilitation process. Rehab Brief 16(6), 1-4.

National Organisation on Disability (2QQG). Survey of the status of people with disabilities in the United States: Employment: Washington, DC: Author.

O'Day, B. (1999). Policy barriers for people with disabilities who want to work American Rehabilitation, 25(1), 8-15.

Par deck, J.T. (2001). An update on the Americans with Disabilities Act: Implications for health and human service delivery. Journal of Health \& Social Policy, 13(4), 1-15.

Rehabilitation Services Administration (1993). The Rehabilitation Act of 1973 as amended by the Rehabilitation Act Amendment of 1992. Washington, D.C, author.

Roessler, R.T. (1987). Work disability and the future. Promoting employment for people with disabilities. Journal of Counseling and Development 66,188-190. 
Ryan, C.P. (1995). Work isn't what is used to be: Implications, recommendations and strategies for vocational rehabilitation journal of Rehabilitation, Oct/Nov./Dev.,815.

Schroder, F.K. (1995), November). Philosophy underpinnings of effective rehabilitation. Sixteen Mary E. Switzer Lecture, Worcester, MA

Scotch, R.K. (1995). Disability policy, An eclectic overview. Journal of Disability policy Studies, 11(1), 6-11.

Society for Human Resource Management (2000). The ADA at work: Implementation of the employment provisions of the Americans with Disabilities Act. Washington, DC: Author.

Szymanski KM, \& Hanley - Marxwell, C. (1996). Career development of people with development disabilities: an ecological model. Journalof Rehabilitation, 62, 48-55.

Szymanski K.M,\& llcrshenson D.B (1997). Career development of people with disabilities: An ecological model. In R.M. Parker \& E.M. Szymanski (Eds.), Rehabilitation counseling: Basics and beyond ( ${ }^{\text {rd }}$ Ed. Pp. 273-304). Austin, TX Pro. Ed.

Szymanski E.M. Hershenson, D.B, Enright, M.S. \& Edtinger, J.M. (1996). Career development theories, constructs, and research Implications for people with disabilities. In E.M. Szymanski, \& R.M. Parker (Eds.), work and Disability: Issues and strategies in career development and job placement (Pp. 79-12666). Austin, TX: Pro. Ed.

Szymanski, KM., \& Trueba, H.T, (1994). Castification of people with disabilities: Potential disempowerment aspects of classification in disability services. Journal of Rehabilitation, July, Aug., Sept, 12-20.

Taylor, H. (1994). N.O.D. Survey of Americans with disabilities. Business Week, Special advertising section.

Trueba, H. (1993). Castification in multicultural America. In H.T. Trueba, C. Rodriguez, Y. Zou, \& J. Contron, Healing multicultural America: Mexican immigrants rise to power in rural California (Pp. 29-51). Philadelphia: Palmer.

Trueba, H. Cheng, L. \& K. (1993).Myth or reality: Adaptive Strategies of Asian Americans in California. London, England; Palmer.

U.S. Equal Employment Opportunity Commission (1992).The Americans with disabilities Act: Questions and Answers. Washington, DC: Author.

Wolfe, K.E. (1997). Career counseling for people with disabilities. Austin, TX: Pro. Ed. 